\title{
O QUE É “CENTRAL” NA EUROPA CENTRAL?*
}

\author{
Zygmunt Bauman \\ Universidade de Leeds, Reino Unido
}

\begin{abstract}
Resumo: Esta comunicação procura ligações entre a europa contemporânea e as suas experiências históricas de estados-nações, sobretudo no que diz respeito a "Ler o Outro". Discutindo - e desafiando - as três principais dimensões europeias - geográfica, política e cultural - o autor salienta a missão/tarefa/meta-arte da Europa - ainda por concretizar por completo - de desenvolver a sua notável "capacidade de viver, permanente e beneficamente, com a diferença cultural: proveitosamente para todos lados, não apesar das suas diferenças, mas graças a elas", bem como de "adquirir e partilhar a arte de aprender com os outros". Encontrando já tais capacidades no Império Romano, esta comunicação centrase particularmente em dois estados europeus modernos, baseados no multiculturalismo e no multinacionalismo: a commomwealth polaco-lituana e o império austro-húngaro. Ambos são discutidos como experiências que devem tornar-se exemplos essenciais para a europa dos nossos dias.
\end{abstract}

Palavras-chave: Europa; União Europeia; nação; estado; mistura cultural; modernidade líquida

Antes de abordarmos cuidadosamente a questão enunciada no título, precisamos de responder a uma outra questão: onde procurar e encontrar a Europa? Responder a esta outra questão é muito mais complicado do que parece - mas não se pode tentar responder convenientemente à questão enunciada no título antes de decidirmos em que base é que atribuímos "centralidade" à europa central - e também sobre o tipo de entidade ou entidades a que temos direito a atribuir esse nome... É a identidade da europa que decide o que é "central” - para a sua história ímpar, para a sua situação atual e para os desafios que enfrenta na entrada para o seu futuro.

No uso contemporâneo, o termo "europa” refere-se a pelo menos três fenómenos diferentes e de modo algum sobrepostos. Um é geográfico, o outro político e o outro, ainda, cultural. Permitam-me considera-los por essa ordem.

"Quem fala da europa está errado: ela é um conceito geográfico" - opinou, com desdém, Otto von Bismarck. Bismarck era um político de cima a baixo, e por isso não é de estranhar que tenha dito o que disse: ele referia-se, afinal, a um "facto bruto" do seu tempo. Nesse tempo, a europa era tudo menos uma realidade política - a única realidade com que Bismark estava preocupado.

\footnotetext{
* Tradução: Belmira Coutinho Revisão: Rui Grácio
} 
Cada noção deve o seu significado à oposição em que se encontra relativamente a outra noção: para Bismarck, no limiar do séc. XX, "ser geográfico" significava "não ser político". A "política” era então, como é agora, contérmino com uma presidência ou com um trono, um kanzlerei, ministérios, um bundestag e uma densa rede de gabinetes governamentais e quasi-governamentais. Acima de tudo, mesmo se Carl Schmitt foi longe de mais, na sua vivissecção francamente detalhada do ato original e da característica distintiva da política, quando a reduziu ao apontar de "um inimigo comum”, ele estava certo ao delinear a essência da política na nomeação e relação com "o Outro" de si mesmo. Podemos dizer que a política tem a ver com a criação e com a manipulação de oposições e com o traçado de fronteiras entre "dentro" e "fora" e, consequentemente, o diferenciar o modo com que cada um dos dois membros da oposição, e também cada um dos lados da fronteira, são encarados. Dentro das suas fronteiras geográficas, tal como elas foram desenhadas pelos cartógrafos, a Europa (i.e., a "europa geográfica”) não desempenhou nenhuma dessas funções: não tinha instituições que tornassem plausível o desempenho dessas funções, ou sequer exequível. Assim sendo Bismarck estava certo ao sugerir que, na sua época, a Europa não era uma realidade política. Embora também não estivesse necessariamente certo ao negar à Europa qualquer outra realidade, exceto a geográfica. Pelo meu lado, iria ainda mais longe e diria que na época de Bismarck a Europa tinha algumas realidades distintas e tangíveis relacionadas com a geografia realidades essas que veio depois a perder - particularmente no último meio século, aproximadamente, em simultâneo com a sua concentração na construção da sua atual realidade política.

Para começar: no decorrer dos últimos cinco séculos, o poderio económico e militar daquela península no noroeste do continente asiático, a que se chamou Europa, tendia a ser coberto pela incontestada posição da Europa enquanto ponto de referência para a avaliação, glorificação ou condenação de todas as formas alternativas de vida humana, passadas e presentes; e, também, como o supremo tribunal onde tais avaliações eram autoritariamente pronunciadas e tornadas obrigatórias. Era suficiente ser-se europeu, diz Ryszard Kapuściński (provavelmente o mais acutilante e perspicaz repórter e registador do estado de coisas no mundo do final do séc. XX) para se sentir como um patrão e um governante em qualquer lugar do mundo. Mesmo uma pessoa medíocre com uma posição humilde e com baixa opinião no seu país nativo (mas europeu!) ascendia às posições sociais mais altas depois de aterrar numa Malásia ou numa Zâmbia... Contudo, tal já não é mais verdade.

Até há muito pouco tempo (os mais velhos de entre nós recordam ainda esses tempos...) a Europa era aquele centro que tornava o resto do planeta numa periferia. 
Tal como Denis de Rougemont duramente o colocoui, a Europa "descobriu", um por um, todos os continentes da terra, mas nenhum continente alguma vez descobriu a Europa; ela dominou todos os continentes sucessivamente, mas nunca foi dominada por nenhum; e ela inventou uma civilização que o resto do mundo tentou imitar, mas o processo inverso nunca (até agora, a nenhum nível) aconteceu. Podemos acrescentar: as guerras europeias, e apenas essas guerras, foram guerras mundiais: os dramas internos europeus eram encenados num palco mundial. Mas isso também já não é verdade.

Até ainda há bem pouco tempo se poderia definir a Europa "geográfica" (na ausência da política), tal como de Rougemont sugeriu há não tanto tempo assim: pela sua "função globalizante”. A Europa foi, durante a maior parte dos últimos séculos, um espaço geográfico singularmente aventureiro, como nenhum outro. Tendo sido o primeiro local da terra que entrou no modo de vida que foi subsequentemente rotulado de "moderno", a Europa criou problemas locais de que nunca ninguém antes tinha ouvido falar e de que ninguém fazia a mais pequena ideia de como resolver. Mas a Europa inventou também o caminho para a sua resolução - ainda que numa forma imprópria a ser universalizada e implantada por terras aonde estes problemas, original e exclusivamente europeus, chegaram mais tarde. Os problemas que a Europa produziu internamente (e muito localmente), a Europa resolveu reciclando outras partes do planeta em fontes baratas de energia, minerais, mercadorias, ou mão-de-obra dócil e económica; mas acima de tudo em sugestões de despejo de resíduos para os subprodutos da modernização - os produtos excessivos e redundantes que ela não poderia usar domesticamente de forma rentável e as pessoas excessivas e redundantes que ela não poderia empregar domesticamente.

Em poucas palavras, a Europa inventou soluções globais para problemas produzidos localmente - mas, tendo-as inventado e praticado durante alguns séculos, no final a Europa forçou todas as outras partes da humanidade a procurar, desesperadamente, mas sem sucesso, soluções locais para os problemas produzidos globalmente.

Mas, uma vez mais, isso já não é verdade. Na realidade, uma das principais considerações que inspiram e estimulam os esforços para dotar a Europa geográfica de uma realidade política foi a perceção de que tinha chegado, para a Europa, bem como para o resto do mundo, o tempo de procurar ou inventar soluções "geograficamente locais" para os problemas produzidos globalmente: soluções eficazes pelo menos localmente. Soluções globais para os problemas produzidos localmente podem estar, em princípio, disponíveis para um número relativamente pequeno de habitantes do planeta, e apenas durante o tempo que esse pequeno grupo desfrutar de superioridade 
sobre todo o resto, beneficiando de um diferencial de poder grande o suficiente para permanecer incontestado (pelo menos não contestado eficazmente) e de ser amplamente considerado como sendo inquestionável. Mas a Europa já não goza de tal privilégio e não pode seriamente esperar recuperar o que perdeu. Foi essa circunstância que acrescentou o impulso mais poderoso à construção da "Europa política" na forma da União Europeia - e que, em grande medida, influenciou e continua a influenciar as apostas e os objetivos da política europeia.

Muito mais do que no tempo das iniciativas originais de Schuman-Monnet-SpaakAdenauer-De Gasperi, a "Europa política", na sua forma atual, precisa de ser entendida como o subproduto de uma queda abrupta da autoconfiança europeia. Foi o desaparecimento da autoconfiança do "nós-podemos-fazer" que despoletou uma aguda explosão de interesse numa "nova identidade europeia" e em "redefinir o papel" da Europa, a fim de corresponder ao atual jogo planetário, um jogo em que as regras e os desafios mudaram drasticamente e continuam a mudar, se bem que já não na iniciativa europeia, ou sob o controle da Europa, e com um mínimo, se tanto, de influência da Europa. Daí decorreu, também, uma onda de sentimentos neotribais que se espalharam de Estocolmo a Roma e de Paris a Budapeste, ampliados e reforçados pelos crescentes medos e alertas do "inimigo às portas" e da "quinta coluna" - e o consequente "espíritoda-fortaleza-sitiada”, que se manifesta na rapidamente crescente popularidade de fronteiras e portas bem fechadas.

Por outro lado, no entanto, a (intermitentemente) emergente Federação Europeia está a enfrentar a tarefa de repetir, numa escala maior (e, portanto, potencialmente planetária) o feito conquistado pelos estados-nação emergentes da modernidade primitiva: voltar a juntar poder e política, que já estiveram estreitamente interligados, mas que foram posteriormente separados, e que têm estado, desde a sua separação, a navegar (ou à deriva) em sentidos opostos. O caminho para a implementação dessa tarefa é tão tortuoso agora como era então - no início da era moderna e no seu estágio de construção de nação e Estado. Agora, tanto quanto nessa altura, o caminho está cheio de armadilhas e salpicado com riscos incalculáveis. O pior de tudo é que este caminho não está cartografado e cada passo sucessivo parece ser como um salto para o desconhecido. E há poucos sinais de vontade política para concluir a tarefa - como ilustrado, por exemplo, pelo enterrar vivo o Tratado de Lisboa através da eleição para os cargos de Presidente do Conselho Europeu e de Alto Representante para a Política Externa e de Segurança de pessoas notáveis principalmente pela sua falta de notabilidade, bem como pela notável, como nunca antes, unânime, equanimidade, com que a nomeação foi recebida nos gabinetes dos 27 governos da Europa. 
Muitos observadores (a maioria?) duvidam da viabilidade de gerar, cultivar, aperfeiçoar e entrincheirar uma "identidade europeia" - uma identidade política, para não mencionar o aspeto espiritual - e têm pouca confiança na hipótese de que esse esforço seja seriamente levado a cabo, muito menos concluído com sucesso. Os céticos não acreditam na viabilidade de uma democracia "pós-nacional", ou de qualquer entidade política democrática acima do nível da nação - insistindo que a fidelidade às normas civis e políticas não substitui "laços etno-culturais"ii e que a cidadania é inviável numa base puramente "civilizacional" (jurídico-política) sem a ajuda de "Eros" (a dimensão emocional) -, assumindo, ao mesmo tempo, que os laços etno-culturais e Eros estão única e inextricavelmente ligados uns aos outros e ao tipo do "sentimento de partilha do-passado-e-do -destino" que entrou para a história com o nome de "nacionalismo". Eles acreditam que a solidariedade de estilo comunal pode atacar as raízes e florescer somente dentro deste contexto e não pode ser reconstruída ou estabelecida novamente de qualquer outro modo. Que a legitimação nacionalista do poder do Estado não foi mais do que um episódio historicamente confinado e do que uma das muitas formas alternativas de possível união política-poder, ou que a moderna mistura de soberania e nacionalismo apresentou mais sintomas de ser um casamento de conveniência do que um veredicto da providência ou uma inevitabilidade histórica, ou de que o casamento em si foi tudo menos uma conclusão predestinada e, quando arranjado, provou ser tão tempestuoso como a maioria dos procedimentos de divórcio tendem a ser - todas essas possibilidades são desse modo indeferidas pelo simples expediente da petição de princípio.

Jürgen Habermas, provavelmente o mais consistente e reconhecido porta-voz da oposição a esse tipo de ceticismo, ressalta, contudo, que

uma ordem democrática não tem que ser inerentemente enraizada mentalmente na "nação" como uma comunidade pré-política de destino partilhado. A força do Estado democrático constitucional reside precisamente na sua capacidade de fechar os buracos da integração social através da participação política dos seus cidadãos. iii

Formulado apenas desta forma, o argumento já soa bastante convincente - e ainda pode ser levado mais longe. A nação, como ansiosamente admitiria qualquer promotor de uma "ideia nacional", é tão vulnerável e frágil sem a proteção de um estado soberano (assegurando a sua mêmeté, identidade contínua) como o estado o seria sem uma nação que legitima as suas exigências de obediência e disciplina. As nações modernas e os estados modernos são produtos gémeos da mesma constelação histórica. Um pode "preceder" o outro apenas por um curto período de tempo, enquanto tenta 
necessariamente fazer esse curto espaço de tempo tão curto quanto possível, preenchendo-o com os esforços para substituir a prioridade pela simultaneidade - ao forçar a marca da equação entre os parceiros aparentemente autónomos. O estado francês foi "precedido" por provençais e bretões, não franceses, o estado alemão por bávaros, saxões ou prussianos, não alemães. Dificilmente os provençais e os bretões se teriam transformado em franceses, os bávaros e os prussianos em alemães, muito menos permanecido franceses ou alemães definitivamente, não fosse a sua reencarnação "assistida" - por, respetivamente, os estados francês e alemão.

Para todos os efeitos e propósitos práticos, tanto as nações como os estados modernos emergiram no curso de dois processos, simultâneos e intimamente ligados, da construção da nação e do Estado; através de nada menos do que por processos transparentes e sem fricção, e de nada menos do que processos com garantia de sucesso a priori. Dizer que o quadro político não pode ser estabelecido sem um organismo etno-cultural viável já em vigor não é nem mais nem menos convincente do que dizer que nenhum organismo etno-cultural é suscetível de se tornar e permanecer viável sem uma estrutura política viável e em funcionamento. O dilema do ovo e da galinha, se é que ele alguma vez existiu. E assim como nem galinha, nem ovo, têm por si seguro contra a extinção ou garantida a existência eterna, ambos só podem continuar a existir em conjunto - enquanto ambos estão condenados à extinção caso um deles morra.

Devido à evaporação de grande parte do poder que anteriormente tinha para o espaço global que Manuel Castells caracteriza como o "espaço de fluxos", o quadro político herdado do Estado-nação tem agora, no entanto, uma crescente dificuldade em sustentar sozinho o organismo "etno-cultural" que, por comum consentimento, é por sua vez o seu companheiro indispensável. A simbiose entre os dois ameaça desmoronar-se, caso fosse para ficar, como antes, limitada ao nível do estado-nação; a maioria das unidades estaduais na Europa, assim como em outros continentes, dispõe atualmente de muito pouco poder para evitar a perda do plâncton - fustigada por marés, não pode nem controlar nem mesmo navegar realmente. Será que o que, claramente, não pode ser alcançado isoladamente, terá talvez melhor hipótese de sucesso se realizado conjuntamente?

Permitam-me recordar-vos uma outra das frases famosas de Otto von Bismarck: "Eu sempre encontrei a palavra "Europa" na boca daqueles políticos que queriam, a partir de outros poderes, algo que não se atrevem a exigir em seu próprio nome". Acredito que, se ainda estivesse vivo, Bismarck iria repetir essa frase com ainda mais segurança. E estaria tão certo hoje como estava há cem anos. Só que, agora, ao contrário do que acontecia no momento que a frase foi originalmente proferida, apenas poucos entre os 
políticos do estado ousariam fazer exigências só em nome dos seus estados (a não ser que dirijam os seus pedidos a Bruxelas ...). E mesmo esses poucos, suponho, têm algumas dúvidas quanto à possibilidade de as exigências feitas nesse nome serem atendidas ser igual à possibilidade das exigências feitas em nome da Europa. Nós (os europeus) somos todos iguais na nossa, distinta, insuficiência - e na nossa necessidade de sermos protegidos/reforçados por um poder maior do que cada um de nós pode ostentar sozinho (mesmo se é verdade que alguns de nós são mais iguais neste aspeto do que outros)... Tal como no tempo do veredicto de Bismarck, a palavra "Europa" pode ser ouvida hoje em dia com mais frequência da boca dos primeiros-ministros de alguns estados do que da boca dos primeiros-ministros de outros. Por outro lado, alguns de nós, ao ouvir a palavra "Europa", sentimo-nos como uns Lombardos ao ouvir a palavra "Itália": a ranger os dentes perante a ideia de partilhar a riqueza, suadamente conquistada, com os preguiçosos, imprevidentes e irresponsavelmente felizes calabreses ou sicilianos...

Se as características essenciais da solidariedade humana (como os sentimentos de pertença mútua e de responsabilidade partilhada para o futuro comum, ou a vontade de cuidar do bem-estar de cada um e para encontrar soluções amigáveis e duráveis para conflitos inflamados esporadicamente) são para ser erguidas do nível de estado-nação e re-focadas num grau superior, europeu, como eu acredito que hoje precisam de ser, elas precisam de um quadro institucional de construção de opinião e de formação da vontade. A União Europeia direciona-se (e movimenta-se - mesmo que a um ritmo irritantemente lento, hesitante, e às vezes de uma forma um-passo-à-frente-e-doispassos-atrás) no sentido de uma forma rudimentar ou embrionária de tal quadro institucional - encontrando em seu caminho, como obstáculos mais obstrutivos, os estabelecimentos políticos de estados-nação existentes e a sua relutância em desfazerse do que resta da sua soberania que já foi plena. A direção atual é difícil de traçar de forma inequívoca, e prognosticar os seus surtos de atividade no futuro é ainda mais difícil, além de ser indevido, irresponsável e - vamos dizê-lo - imprudente.

Uma coisa parece ser relativamente clara, todavia. Seja ou não decorrente de raízes étnicas, o estímulo à integração política e o fator indispensável para mantê-lo em curso deve ser um sentimento/visão partilhados de uma missão coletiva: uma missão única, que apenas pode ser feita dentro do corpo político projetado e que só com a ajuda desse corpo poderá ser realizada. Existe uma tal missão - uma missão digna - que a Europa poderia realizar, e que pela sua história e pelas suas qualidades atuais está predestinada a realizar? 
A Europa não pode considerar seriamente equiparar-se ao poderio militar americano, nem pode esperar recuperar o seu domínio industrial do passado, irremediavelmente perdido no nosso mundo cada vez mais policêntrico - um mundo agora sujeito aos processos de modernização económica na sua totalidade. Todavia, pode tentar, e deve tentar, tornar o planeta hospitaleiro para outros valores e outros modos de existência diferentes dos representados e promovidos pela superpotência militar americana; para os valores e modos que a Europa está, mais do que qualquer outra parte do mundo, predisposta a oferecer ao mundo que, mais do que qualquer outra coisa, precisa de projetar, abraçar e seguir a estrada que conduz à allgemeine Vereinigung der Menschheit e à paz perpétua de Kant. Bem, além de ser uma entidade geográfica e (possivelmente) política, a Europa é também uma entidade cultural.

George Steiner insiste que o desígnio da Europa "é o do espírito e do intelecto"iv. "O génio da Europa é o que William Blake teria chamado de 'a santidade do particular minucioso'. É o da diversidade linguística, cultural, social, o de um mosaico pródigo que muitas vezes faz de uma distância trivial, $20 \mathrm{~km}$ de distância, uma divisão entre os mundos... A Europa vai realmente morrer se não lutar pelas suas línguas, tradições locais e autonomias sociais: se esquecer que 'Deus está nos detalhes'."

Pensamentos semelhantes podem ser encontrados no legado literário de Hans-Georg Gadamerv . É a sua variedade, a sua riqueza quase excessiva, aquilo que Gadamer coloca no topo da lista dos méritos únicos da Europa; ele vê a profusão de diferenças como o principal entre os tesouros que a Europa preservou e pode oferecer ao mundo. "Viver com o Outro, viver como o Outro do Outro, é a tarefa fundamental do ser humano tanto nos níveis mais humildes como nos níveis mais elevados... Daí, talvez, a vantagem particular da Europa, que pode e teve que aprender a arte de viver com os outros". Na Europa, como em nenhum outro lugar, "o outro" esteve e está sempre perto, na visão e ao estender do braço; metaforicamente ou mesmo literalmente, o Outro é um vizinho do lado - e os europeus não podem deixar de negociar os termos dessa vizinhança apesar da alteridade e das diferenças que os separam. O cenário europeu marcado pelo "multilinguismo, a vizinhança próxima do Outro, e igual valor concedido ao outro num espaço bem restrito" poderia ser visto como uma escola, da qual o resto do mundo pode muito bem retirar conhecimento e habilidades fundamentais que fazem a diferença entre a sobrevivência e a morte. Adquirir e partilhar a arte de aprender uns com os outros é, na opinião de Gadamer, "a tarefa da Europa". Eu acrescentaria: a missão da Europa, ou mais precisamente, o desígnio da Europa à espera de ser reformulado em destino. 
Impossível de exagerar a importância desta tarefa, e a importância da determinação da Europa para realizá-la enquanto "condição decisiva de resolver problemas vitais do mundo moderno", uma condição verdadeiramente sine qua non, só a amizade e "solidariedade flutuante" podem assegurar "uma estrutura ordenada" da coabitação humana. Enfrentando essa tarefa, podemos, e precisamos, de procurar inspiração para o nosso património europeu comum: nos gregos antigos - para quem, como nos lembra Gadamer, o conceito de "um amigo" "articulava a totalidade da vida social". Os "amigos" tendem a ser mutuamente tolerantes e compreensivos. Os amigos são pessoas capazes de serem amigos uns dos outros apesar das diferenças, e de serem úteis ao outro apesar de, ou antes por causa, das suas diferenças - e de serem simpáticos e atenciosos sem renunciarem à sua singularidade, ao mesmo tempo que nunca permitem que a singularidade os separe dos outros e os coloquem em oposição a eles.

Mais recentemente, Lionel Jospin ${ }^{\text {vi }}$ manifestou esperança numa nova importância mundial da Europa no que respeita à sua "abordagem diferenciada às realidades atuais". A Europa aprendeu, disse ele, da maneira mais difícil e com um preço enorme (pago na moeda do sofrimento humano) "como ultrapassar antagonismos históricos e resolver pacificamente os conflitos" e como reunir "uma vasta gama de culturas" - e viver com uma perspetiva de diversidade cultural permanente deixou de ser visto apenas como um irritante temporário. Vamos notar que estas são precisamente o tipo de lições que o resto do mundo tanto necessita.

Quando visto no contexto do planeta cheio de conflitos, a Europa parece um laboratório, onde as ferramentas necessárias para a unificação universal da humanidade de Kant continuam a ser projetadas e como uma oficina onde elas continuam a ser "testadas em ação", mesmo que que agora com um desempenho menos ambiciosos e de menor escala. As ferramentas que atualmente são forjadas e postas à prova dentro da Europa servem, acima de tudo, a delicada operação (para alguns observadores menos otimistas, demasiado delicada para qualquer coisa mais do que uma oportunidade desportiva de sucesso) de separar as bases da legitimidade política, o processo democrático e a vontade para uma partilha de ativos ao estilo comunitário, do princípio da soberania nacional/territorial da qual eles foram, durante a maior parte da história moderna, indissociáveis.

Este desafio, no entanto, enfrenta um mundo muito diferente daquele em que os nossos ancestrais se lançaram a construir modernos "corpos políticos" - os Estados-nação. Seja o que for que se possa dizer quanto à Europa enfrentar esse desafio, isso não será 
certamente que a Europa está indivisa e em pleno controlo do território que as suas instituições administram. As cidades europeias e, particularmente, as megacidades como Londres, são atualmente caixotes de refugo, onde os problemas gerados pela globalização são despejados para reciclagem ou incineração; embora sejam, também, laboratórios em que a arte de viver com esses problemas é experimentada, posta à prova e desenvolvida (por vezes com êxito, mas sempre com esperança). Nenhuma dessas duas funções foi assumida voluntariamente por tais cidades, por sua própria iniciativa; nem os conselhos municipais são capazes de rejeitá-las e recusar-se a desempenhá-las. Uma das tarefas mais difíceis "terceirizada" aos municípios por processos de globalização é a de enfrentar o heterogéneo, o multiétnico, o multilingue e toda a composição multicultural de espaço-de-vida-e-de-trabalho: o resultado da migração maciça provocada pela propagação globalizada da modernização conhecida pela sua intensa produção de "pessoas redundantes", a quem os seus países de origem não puderam ou não quiseram, por um ou outro motivo, acomodar.

Houve três fases distintas na história da migração da era moderna.

A primeira onda de migração seguiu a lógica da síndroma tripartite: territorialidade de soberania, identidade "enraizada", postura de jardinagem, (posteriormente referida, por razões de brevidade, como TIP). Essa foi a emigração a partir do centro "modernizado" (leia-se: o local de construção da ordem e do progresso-económico - as duas principais indústrias geram, e acabam com, o crescente número de "seres humanos desperdiçados'), em parte exportação, em parte despejo de até 60 milhões de pessoas, uma quantidade enorme pelos padrões do século XIX, para "terras vazias" (leia-se: terras cuja população nativa poderia ser removida dos cálculos dos "modernizadores"; ser, literalmente, incontável e ausente, presumivelmente inexistente ou irrelevante). Nativos residuais que sobreviveram aos massacres e epidemias em massa tinham sido elencados pelos imigrantes de países "modernizados" como objetos da "missão civilizadora do homem branco".

A segunda onda de migração poderia ser melhor caracterizada como um caso de "Império contra-emigra". No curso da retração e desmantelamento dos impérios coloniais, um número de povos indígenas em vários estágios de "evolução cultural" seguiu os seus superiores coloniais para a metrópole. Na chegada, eles foram inseridos no único molde de cosmovisão estratégica disponível: um construído e praticado no início da época de construção da nação para lidar com as categorias destinadas à "assimilação": um processo que visa a aniquilação da diferença cultural, colocando as "minorias" no papel de recetoras de cruzadas culturais, missões Kulturkämpfe e proselitistas (atualmente renomeadas, por causa do "politicamente correto", como 
"educação para a cidadania" que visa a "integração"). Esta história ainda não está acabada: uma e outra vez os seus ecos reverberam nas declarações de vontade dos políticos, famosos pela sua inclinação de seguir os hábitos da coruja de Minerva, conhecida por estender as suas asas no final do dia. Depois do padrão da primeira fase da migração, tenta-se ocasionalmente, embora em vão, encaixar o drama do "império contra-migra" no agora desatualizado quadro da síndrome TIP (território, identidade enraizada, estratégia de jardinagem).

A terceira onda de migração moderna, agora em pleno vigor e ainda a ganhar impulso, leva contudo à era das diásporas: um arquipélago mundial de colonatos étnicos/religiosos /linguísticos - ignorantes dos caminhos abertos e estabelecidos pelo episódio imperialista-colonial e seguindo em vez disso a lógica induzida pela globalização da redistribuição planetária dos recursos de vida. As diásporas estão dispersas, difusas, estendem-se por muitos territórios nominalmente soberanos, ignoram as reivindicações dos povos recetores da supremacia de exigências e obrigações locais, estão bloqueadas pelo vínculo duplo (ou múltiplo) de "nacionalidade dupla (ou múltipla)" e lealdade dupla (ou múltipla). A migração de hoje difere das duas fases anteriores, movendo-se nas duas direções (praticamente todos os países, incluindo Grã-Bretanha, são hoje em dia simultaneamente de 'imigrantes' e 'emigrantes'), e não privilegiando rotas (as rotas já não são determinadas pelas ligações imperiais/coloniais do passado). Difere também no facto de explodir com a velha síndrome TIP e substituí-la com uma EAC (extraterritorialidade que afasta a fixação territorial das identidades, 'âncoras' que tiram o lugar das "raízes" como principais ferramentas de identificação, a estratégia de caçador que substitui a postura de jardineiro).

A nova migração lança um ponto de interrogação sobre o vínculo entre identidade e cidadania, indivíduo e local, vizinhança e pertença. Jonathan Rutherford, observador claro e perspicaz dos quadros de convívio humano em rápida mudança, observa ${ }^{\text {vii }}$ que os moradores da rua em que vive, em Londres, formam uma

vizinhança de diferentes comunidades, algumas com redes que se estendem apenas para a rua ao lado, outras que se estendem pelo mundo. É um bairro de fronteiras porosas em que é difícil identificar quem pertence e quem é de fora. O que significa "nós pertencemos" nesta localidade? A que é que cada um de nós chama de casa e, quando pensamos no passado e nos lembramos de como chegamos aqui, quais são as histórias que vamos partilhar?

Viver como o resto de nós (ou a maioria desse resto) numa diáspora (com que extensão, e em que sentido(s)?), entre diásporas (com que extensão, e em que sentido(s)?) forçou 
a que, pela primeira vez, fosse incluída na agenda a questão da "arte de viver com a diferença" - que pode aparecer na agenda apenas depois da diferença não ser mais vista como uma irritação meramente temporária, e assim necessitando urgentemente, ao contrário do que acontecia no passado, da composição de novas artes e habilidades, bem como de ensino e aprendizagem árduos. A ideia de "direitos humanos", promovida no cenário EAC para substituir ou, pelo menos, complementar as instituições da era TIP da cidadania territorialmente determinada é hoje traduzida como o "direito de permanecer diferente". Com um progresso irregular, a nova interpretação da ideia de direitos humanos sedimenta, na melhor das hipóteses, a tolerância; ainda não começou seriamente a sedimentar a solidariedade. E é uma questão discutível se ela está apta a conceber a solidariedade de grupo em qualquer outra forma que não a de "redes" predominantemente virtuais, soltas, instáveis e desgastadas, galvanizadas e continuamente remodeladas pela ação combinada da conexão e desconexão individuais, fazendo apelos e recusando-se a responder-lhes.

A nova versão da ideia de direitos humanos desmonta hierarquias e desfaz a imagem da evolução cultural "ascendente" ("progressista"). As formas de vida flutuam, encontram, chocam, colidem, agarram-se umas às outras, fundem-se e alienam com (parafraseando Georg Simmel) igual gravidade específica. Hierarquias e linhas evolutivas estáveis e firmes são substituídas por batalhas de reconhecimento intermináveis e endemicamente inconclusivas; no máximo, com ordens hierárquicas eminentemente renegociáveis. Imitando Arquimedes, do qual se diz que insistia (provavelmente com uma espécie de desespero que só uma nebulosidade total do projeto pode causar) que iria virar o mundo de cabeça para baixo se tivesse um ponto de apoio suficientemente sólido, podemos dizer que enunciaríamos quem é que vai assimilar a quem, quem cuja dissimilaridade/idiossincrasia está destinada a um corte e de quem é a que vai emergir no topo, se tivéssemos uma hierarquia de culturas. Bem, não a temos, e é improvável que a venhamos a ter em breve.

Podemos dizer que a cultura está na sua fase líquido-moderna feita à medida da (voluntariamente perseguida, ou suportada como obrigatória) liberdade de escolha individual. E que se destina a atender a tal liberdade. E que a responsabilidade, a companheira inalienável da livre escolha, fica onde a condição líquido-moderna a forçou a ficar: sobre os ombros do indivíduo, agora nomeado gerente único da "política da vida". E que se destina a fazer com que a escolha permaneça inevitável: uma necessidade de vida e um dever; mas também com que ela se torne e permaneça uma tarefa plausível e viável - uma tarefa pela qual os europeus com prazer mediriam o seu progresso e uma tarefa ao seu alcance. 
Eu sugiro que o futuro da Europa política paira sobre o destino da cultura europeia. Há alguns séculos, a Europa colocou a "cultura" ao serviço dos esforços correspondentes, intimamente ligados, de construção da nação e de construção do Estado; antes de mais nada como um agente de homogeneização ou mesmo uma "Gleichschaltung" - visando a unidade política através do nivelamento por cima da diversidade cultural existente. Com a política de assimilação forçada a não ser mais viável, e uma tendência de assimilação voluntária já não plausível devido ao achatamento da anteriormente assistida hierarquia de culturas e da dissipação de "sistemas culturais" anteriormente assistidos, a composição cada vez mais diaspórica do espaço geográfico em expansão da Europa augura a forma do que está para vir - com todos os seus desafios, oportunidades e ameaças. A herança atualmente concebida da Europa para o futuro do mundo é a sua capacidade (longe de ser perfeita, mas a crescer implacavelmente) para viver, de forma permanente e benéfica, com a diferença cultural: rentável para todos os lados não apesar das suas diferenças, mas graças a elas. A Europa pode oferecer ao planeta globalizado o seu know-how sobre alcançar a unidade ao mesmo tempo que se deixa para trás antagonismos ossificados, a sua experiência na conceção e cultivo do sentimento de solidariedade, a ideia de interesse comum e a imagem de uma missão partilhada - não através do denegrir da variedade cultural e não com a intenção de a sufocar, mas através da sua promoção ao posto de algo com valor incontestável e com a intenção de protegê-la e cultivá-la. A Europa aprendeu (e continua a aprender) a arte de transformar a diferenciação cultural de uma desvantagem para a convivência num recurso vantajoso para ela - uma arte de que o nosso planeta precisa de mais do que qualquer outra, uma verdadeira meta-arte, a arte cuja posse permite o desenvolvimento e aquisição de todo o resto das artes salva-vidas e de suporte de vida...

Esta não é, com certeza, uma situação totalmente sem precedentes nas terras abrangidas pela noção resumida de "Europa". Na verdade, foi evidente e afirmado desde o início da história da Europa - e desde o início foram diligentemente procuradas e postas em prática com sucesso formas de lidar com essa situação (mesmo se, posteriormente, uma e outra vez, esses esforços e os seus méritos chegaram a ser postos de lado e esquecidos durante séculos). Se acreditarmos em Tito Lívio, a ascensão de Roma a partir de começos humildes a uma estatura e glória ecuménicas deveu-se à prática regular de concessão de plenos direitos de cidadania e acesso irrestrito aos mais altos cargos do país em expansão a todos os povos conquistados e anexados, ao mesmo tempo prestando o devido tributo aos deuses a quem os recém-chegados adoravam e endossando os ritos do seu culto - e assim fechando o longo histórico de inimizade 
mortal e difamação mútua necessárias no passado para justificar a continuação das hostilidades. Durante cinco séculos ou mais da história antiga da Europa, para muitos observadores a sua época mais magnífica, uma maioria crescente da Europa vivia dentro do escudo protetor da Pax Romana, onde a soma total dos direitos de cidadania igualitários e ilimitados foi concedida à população de todos os países recémconquistados/admitidos, enquanto as estátuas dos seus deuses foram adicionadas, sem margem para dúvidas, ao panteão romano, garantindo assim o crescimento contínuo em número e em versatilidade das divindades que guardavam a integridade e desse modo também a prosperidade do Império Romano. Essa tradição romana de respeito pela alteridade do outro e do estado florescente-através-da-variedade (isto é, alcançar a solidariedade dos cidadãos graças a, não apesar das suas diferenças) não foi, no entanto, como já foi mencionado, continuamente observada ao longo da história europeia.

Enquanto os estados absolutistas emergentes no Oeste da Europa geográfica estavam envolvidos em muitas décadas de guerras sangrentas, devastadoras e semeadoras-desementes-de-inimizade-hereditária religiosa, levando à decisão do colonato de Vestfália de atribuir a cada governante pleno direito de impingir, a bem ou a mal, as suas escolhas religiosas (e assim, por procuração, culturais) aos governados, uma grande parte da Europa a leste do Elba conseguiu no entanto escapar à tendência. Essa parte da Europa defendeu a sua tolerância religiosa (e, portanto, em substância, cultural avant la léttre) e autonomia comunal. Um exemplo privilegiado de tal alternativa era a "República das Duas Nações" polaco/lituana, generosa nos direitos de autogovernos culturais e autopreservação da identidade infundida sobre as suas inúmeras minorias étnicas, linguísticas e religiosas - e, deste modo, escapando às iniquidades, derramamento de sangue e outros horrores das várias guerras religiosas que desfizeram a parte ocidental da Europa e a cobriram de feridas espirituais que levaram séculos a cicatrizar. Esta tradição, todavia, sofreu um fim abrupto com a distribuição da fortaleza de tolerância Polaco-Lituana pelos seus vorazes vizinhos - os impérios dinásticos com aspirações a Estado-nação; no rescaldo da distribuição, culturas anteriormente autónomas, pequenas e grandes, foram submetidas, respetivamente, a uma russificação forçada no seu lado oriental e a uma germanização igualmente implacável no Ocidente, encimadas pela (no geral sem sucesso, mas nem por isso menos ardente) ofensiva anticatólica de, respetivamente, as igrejas Cristã Ortodoxa e Luterana.

Exatamente o quanto a modernidade em avanço foi sincera na sua intenção declarada de promover a causa da liberdade, tal é discutível e permanece uma questão sujeita a debate mas, para além de disputa, está a sua propensão à intolerância cultural - na 
verdade, a inseparável outra face do projeto de "construção da nação". É verdade que foi através da parte indivisível e integrante dos projetos irmãos, mutuamente apoiados e reforçados, de construção da nação e do Estado que as línguas nacionais viriam ser formadas, através da repressão e deslegitimação de "dialetos" comunais, igrejas estatais concebidas através da discriminação e extermínio de "seitas ", ou memória nacional constituída através do rebaixamento e esquecimento de "loucuras e/ou superstições locais".

Uma parte da Europa - mais próxima do que qualquer outra do seu "centro geográfico" - resistiu no entanto também ao ataque maciço à ideia de cultura como uma questão de escolha individual de autoafirmação e da fundação da autonomia individual. Foi a Austro-Hungria, governada a partir de Viena, não por acaso, a estufa de criatividade cultural e incubadora das contribuições de longe mais interessantes e seminais para a Filosofia, Psicologia, Literatura, Música, Artes visuais e de palco europeias... Foi também a área em que a prática da igualdade e auto governação das culturas foi elevada, pelas mentes mais perspicazes da época, ao posto de um modelo para o futuro da Europa; modelo construído com a intenção, e esperança, de limpar a coexistência das nações europeias da terrível fusão de identidade cultural com a soberania territorial.

O princípio da autonomia pessoal nacional ("princípio pessoal") foi longamente elaborado por Otto Bauer, no seu livro de 1907 "Die Nationalitätenfrage und die Sozialdemokratie". Este princípio foi visto por ele como uma maneira de "organizar nações não em corpos territoriais, mas em simples associação de pessoas", deste modo separando radicalmente o país do território e fazendo da nação uma associação nãoterritorial - essa ideia foi oferecida a discussão pública oito anos antes por outro "austromarxista", Karl Renner, no seu ensaio de 1899 "Staat und Nation", e três anos depois por um líder do Bund (União Judaica Trabalhista), Vladimir Medem no seu ensaio de 1904 "Democracia social e a questão nacional" (escrito e publicado em iídiche), um texto que reúne e sintetiza experiências históricas da União Polaco-Lituana e da Monarquia Austro-Húngara:

Tomemos em consideração o caso de um país composto por vários grupos nacionais, por exemplo, polacos, lituanos e judeus. Cada grupo nacional criaria um movimento separado. Todos os cidadãos que pertencem a um determinado grupo nacional adeririam a uma organização especial que iria realizar assembleias culturais em cada região e uma assembleia cultural geral para todo o país. Às assembleias seriam dados poderes financeiros próprios: ou cada grupo nacional teria direito a aumentar os impostos sobre os seus membros, ou o Estado alocaria 
uma percentagem do seu orçamento global para cada um deles. Todos os cidadãos do estado pertenceriam a um dos grupos nacionais, mas a questão de a qual movimento nacional aderir seria uma questão de escolha pessoal e nenhuma autoridade teria qualquer controle sobre a sua decisão. Os movimentos nacionais estariam sujeitos à legislação geral do Estado, mas seriam autónomos nas suas próprias áreas de responsabilidade e nenhum deles teria o direito de interferir nos assuntos dos outros. viii

Tais esperanças foram destruídas e tais planos foram afogados no sangue derramado nas trincheiras da Grande Guerra. Veio a Conferência de Paz de Versailles e o memorável veredito de Woodrow Wilson de que a soberania das nações é o preceito universal da humanidade e precisa de ser aceite como a chave para a reconstrução pósguerra - um veredito que deixou Hannah Arendt famosamente perplexa e horrorizada, dolorosamente ciente e consciente de que pertencia aos "cintos de população mista" que eram singularmente impróprios para a aplicação do critério "ein Volk, ein Reich"ix. Mesmo a ignorância de Wilson (ou seria desdém ou arrogância?) não foi suficiente, todavia, para evitar outra tentativa (embora tímida, com certeza) de procurar e encontrar um modo de convivência mais adequado à condição de sobreposição e entrecruzamento dos arquipélagos de diásporas, na forma do estado jugoslavo multiétnico. Foi ainda necessário uma divagação casualmente dita por Helmut Kohl num momento de descuido (implicando que a Eslovénia merecia independência porque era etnicamente homogénea) para abrir outra caixa de Pandora de massacres de bairro e limpezas étnicas...

Nós, europeus, estamos hoje na era emergente das diásporas, a enfrentar a perspetiva de a Europa ser transformada num "cinto de população mista" em constante crescimento e alongamento. Ao contrário da anterior direção do pêndulo, este processo presente não é assistido (pelo Estado); muito pelo contrário, os poderes do Estado tentam, tanto quanto podem, retardar o processo ou levá-lo a um impasse - mas a capacidade à sua disposição fica evidentemente cada vez mais muito aquém do que seria necessário para deter a maré da rápida e imparável globalização da interdependência humana. As respostas "pró-ativas" à "diasporização" dos ambientes sociais são lentas, hesitantes, têm falta de visão e, acima de tudo, são muito poucas e distantes entre si, se medidas pela sua importância e urgência: e, contudo, é precisamente este o contexto em que as perspetivas da Europa como entidade política e cultural, a localização exata do "centro" da Europa, precisam de ser deliberadas e debatidas. É na parte da Europa que reclama o qualificador "Central" que a experiência de identidade comunitária, separada da questão da administração territorial, está relativamente fresca na memória e (talvez) os hábitos adquiridos, praticados e 
apreciados na época de coabitação livre de pressões Kulturkämpfe e de assimilação, sejam suficientemente recentes para serem lembrados e readotados.

É a memória da Europa Central que mostra o futuro da Europa... Pode imaginar uma centralidade mais central do que esta?!

i Vide Denis de Rougemont, 'L'aventure mondiale des Européens' (orig.1962), in Écrits sur l'Europe, Editions de la Difference, Paris 1994.

ii Vide, por exemplo, Cris Shore, 'Wither European Citizenship?', in European Journal of Social Theory Fevereiro de 2004, pp.27-44.

iii Jürgen Habermas, The Postnational Constellation: Political Essays, transl. by Max Pensky, Polity Press 2001, p.76.

iv Vide George Steiner, The Idea of Europe, Nexus Institute 2004, pp.32-4.

v Vide, em particular, Das Erbe Europas (Suhrkamp 1989) de Hans-Georg Gadamer - aqui citado a partir da tradução francesa de Philippe Invernel, L'heritage de l'Europe, Rivages poche 2003, pp. 40 \& 124.

vi Vide Lionel Jospin, 'Solidarity or playing solitaire', The Hedgehog Review Primavera de 2003, pp.32-44.

vii Jonathan Rutherford, After Identity, Laurence \& Wishart 2007, pp. 59-60.

viii Como citado recentemente na Wikipédia a partir de "Choose Your Own Nationality or The Forgotten History of Cultural Autonomy" de Yves Plassereaud, na edição inglesa do Le Monde diplomatique de Maio de 2000.

ix Vide Hannah Arendt, The Origins of Totalitarianism, Andre Deutsch 1986, p.270.

Zygmunt Bauman é sociólogo e filósofo da cultura, conhecido pela vasta obra dedicada ao pós-modernismo, conceptualizado através do termo próprio modernidade líquida, e dedica também atenção ao papel da Europa no mundo globalizado. 